\title{
First record of Columbus crab Planes minutus (Crustacea: Decapoda: Brachyura: Grapsidae) Linnaeus, 1758 for the northwestern Indian Ocean
}

\author{
Fadi Yaghmour ${ }^{1 *}$ and Halima Al Naqbi ${ }^{2}$
}

\begin{abstract}
Planes minutus Linnaeus, 1758 is a species of grapsid crab that is known to be symbiotically associated with various species that include but are not limited to sea turtles. This specie is known to occur in tropical and subtropical oceans. In this study, we report a P.minutus specimen from a stranded loggerhead sea turtle from the Sea of Oman coast of the United Arab Emirates, signifying the first record of this specie from the Northwestern Indian Ocean.
\end{abstract}

\section{Introduction}

Grapsoid and ocypodoid crabs are considered to be the two most dominant brachyuran taxa in intertidal zones of the Arabian Gulf and the Sea of Oman (Al-Ghais and Cooper 1996). There, grapsoid crabs are represented by four families (Sesarmidae, Plagusiidae, Varunidae, and Grapsidae), nine genera (Chiromantes, Nanosesarma, Parasesarma, Perisesarma, Plagusia, Metaplax, Thalassograpsus, Grapsus and Metopograpsus) and 12 species (Naderloo 2011; Naderloo and Turkay 2012; Naderloo 2017). Species of the Grapsidae family typically occupy the littoral zone on rocky areas and estuarine waters (Naderloo and Turkay 2012). However, the two members of the Planes genus, neither of which have been recorded in the region, occur in association with flotsam and marine fauna (Carpenter 2014).

Crabs of the Planes genus are known to live on numerous floating objects including buoys, timber, feathers and tarballs and are known to live symbiotically on marine animals such as jellyfish, siphonophores, gastropods and marine turtles (Davenport 1994; Bas 1999; Frick et al. 2004). Planes minutus is known to occur in all

\footnotetext{
* Correspondence: fadi.mohd@epaa.shj.ae; fadi.epaa@gmail.com ${ }^{1}$ Hefaiyah Mountain Conservation Centre (Scientific Research Department), Environment and Protected Areas Authority, Sharjah, United Arab Emirates Full list of author information is available at the end of the article
}

tropical and subtropical oceans and was observed associated with marine turtles in the South Atlantic, Pacific Ocean, and Indian Ocean (Fig. 1) (Frick et al. 2001). However, in the Indian Ocean, observations were limited to the coasts of Somalia and South Africa and none of which were in association with marine turtles (Branch et al. 1994; Pfaller et al. 2019a, 2019b). In this study, we present the first published record of Planes minutus for the Sea of Oman and the Northwestern Indian Ocean.

\section{Materials and methods Specimen sampling}

On Thursday, 11th of January 2018, a stranded sea turtle was discovered by the Environment and Protected Areas Authority rangers on the beach of the Alqurm Wa Lehaffaiiah Protected Area (GPS: $\left.24.984419^{\circ} \mathrm{N}, 56.373445^{\circ} \mathrm{E}\right)$ in the city of Kalba, Sharjah, United Arab Emirates (Fig. 2a). The external morphologic features of the specimen- two pairs of prefrontal scutes, five lateral scutes, two claws on each fore-flipper and 3 inframarginal scutes without pores- confirm that the specimen was a loggerhead sea turtle Caretta caretta. The stranding was fresh (condition code 1 as per the NetCet "Standard Protocol for Postmortem Examination on Sea Turtles" (Poppi and Marchhiori 2013). During the post mortem examination process, a live female crab was observed settled on the dorsal surface 


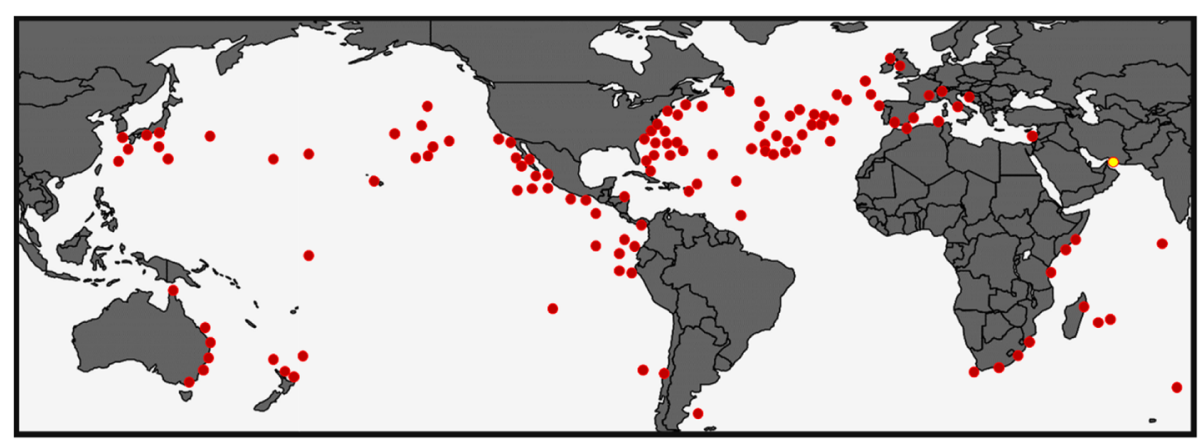

Fig. 1 Global distribution of Planes minutus (red) including the observation from this study (yellow). References largely adopted from Chace (1951) and WoRMS (2020) and references therein

of the turtle's tail (Fig. 2b). The specimen was sampled opportunistically and examined closely for species identification. The morphologic features of the specimen were documented and compared to those in existing literature. The sampled crab specimen was identified as Planes minutus Linnaeus, 1758 (Fig. 2c), a species of grapsid crab that is occasionally observed associated with hawksbill sea turtles Eretmochelys imbricata and green sea turtles Chelonia mydas, and is known to be symbiotically associated with olive ridley sea turtles Lepidochelys olivacea and
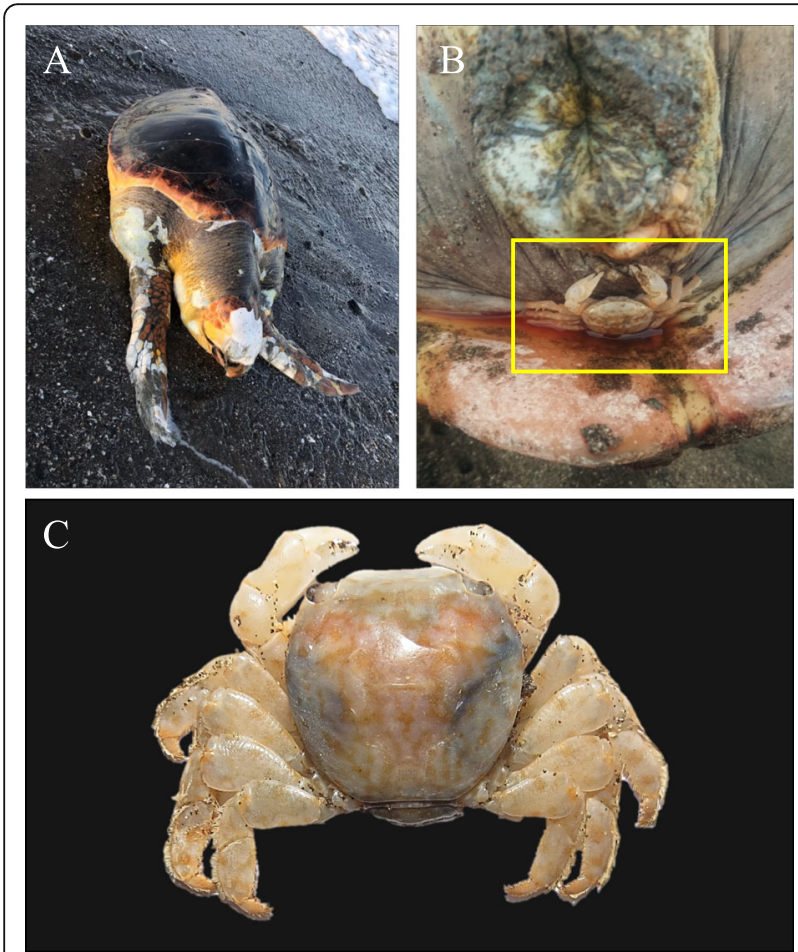

Fig. 2 Female Planes minutus Linnaeus, 1758 [a] collected from the dorsal surface of the tail [b] of a stranded loggerhead sea turtle [c] at the Alqurm Wa Lehhaffaiiah Protected Area on the 11th of January 2018 (CW = 21 mm; CL=20 mm) (Photos: Fadi Yaghmour \& Rashid Marashda, 2018) loggerhead sea turtles C. caretta (Dellinger et al. 1997; Pfaller et al. 2019b).

\section{Sample analysis}

The crab was identified visually and photographed using a Dino-Lite AM7915MZT digital microscope while carefully referring to available identification guides and keys all the while noting recent development in the specie's taxonomy (Chace 1951; Branch et al. 1994; Carpenter 2014; Pfaller et al., 2019b).

\section{Results}

\section{SYSTEMATICS}

Phylum ARTHROPODA von Siebold, 1848

Class CRUSTACEA Brünnich, 1772

Order DECAPODA Latreille, 1802

Family GRAPSIDAE MacLeay, 1838

Genus Planes Bowdich, 1825

Species minutus Linnaeus, 1758 (Figs. 2 and 3)

\section{Morphology (see Fig. 3)}

The carapace width is about as wide as the carapace length; according to (Chace 1951), the carapace length: carapace width ratio equals to 1:0.91-1.12 which is about the ratio found in our specimen (Carapace Length: $20.0 \mathrm{~mm}$; Carapace Width: $21.0 \mathrm{~mm}=1: 1.05)$. The front is more than half the carapace width (Fig. 3b) (Carpenter 2014). Specimen has small inner suborbital lobe with antenna entering the orbit. The dorsal surface of the carapace is almost smooth, lacking transverse grooves, ridges or granulations. The lateral margins of the carapace are convex (Fig. 3b), with surface of branchial regions faintly striate. The walking legs, strongly fringed with hairs, are long, slender and flattened (Chace 1951; Carpenter 2014). Propodus of last walking leg about 2 times as long as its maximum width (Fig. 3d) (Carpenter 2014). Chelae with prominent sharp granules around the lower margins with fixed finger bent abruptly downward (Fig. 3c) (Chace 1951). 


\section{Discussion}

Crabs of the Planes genus are relatively small and can inhabit most floating objects in the open ocean. The relative abundance of these oceanic crabs is somewhat dependent on the abundance of floating objects and swimming organisms. The implications of the spread of anthropogenic marine debris may be relevant to the ecology of this specie. The observation of crabs of this genus on the tail or hind legs of sea turtles has suggested to some researchers that they may ingest the excrement of their host while other dietary studies suggest that they may also ingest the sessile epibiota on the host turtle's carapace and hunt neustonic organisms that swim close to the host turtle (Crane 1937; Frick et al. 2001).

Recent molecular studies suggest that the Planes genus currently has only two valid species, $P$. minutus and P.marinus; with previously known species, like $P$. cyaneus or $P$. major, being presently accepted as $P$. minutus (Pfaller et al., 2009b). The absence of remarkable striations on the branchial surfaces in this specimen indicate that the specimen is $P$. minutus and not P. marinus (Carpenter 2014). The specimen described in this paper is very similar to specimens that are described and illustrated by Chace (1951) and Carpenter (2014). The absence of crabs from this genus from previous studies on Grapsoid biodiversity from the Arabian Gulf and the Sea of Oman are perhaps due to the absence of research efforts in the investigation of chelonian epibiota. However, one previous study that included investigations of nesting loggerhead sea turtles from Oman seem to suggest that $P$. minutus does not occur in association with loggerheads from the Sea of Oman (Pfaller et al. 2019a, 2019b). In fact, no documented record of this specie exists for the entire Northwestern Indian Ocean and none of the observations from the Indian Ocean were in association with marine turtles (Chace 1951). Though this is yet another observation of $P$. minutus from the Indian Ocean, this is the first record of $P$. minutus from the Sea of Oman and the Northwestern Indian Ocean.

\section{Conclusions}

This paper has described a new occurrence of $P$. minutus from the Eastern coast of the UAE, thus expanding the documented global distribution range of this specie to the Sea of Oman and Northwestern Indian Ocean. The frequency and nature of the symbiotic interactions of this specie with marine turtles in the Sea of Oman remains unknown and requires further sightings. However, this record does imply that this specie may occur in association with loggerhead sea turtles in the region that contains one of their most important nesting rockeries.
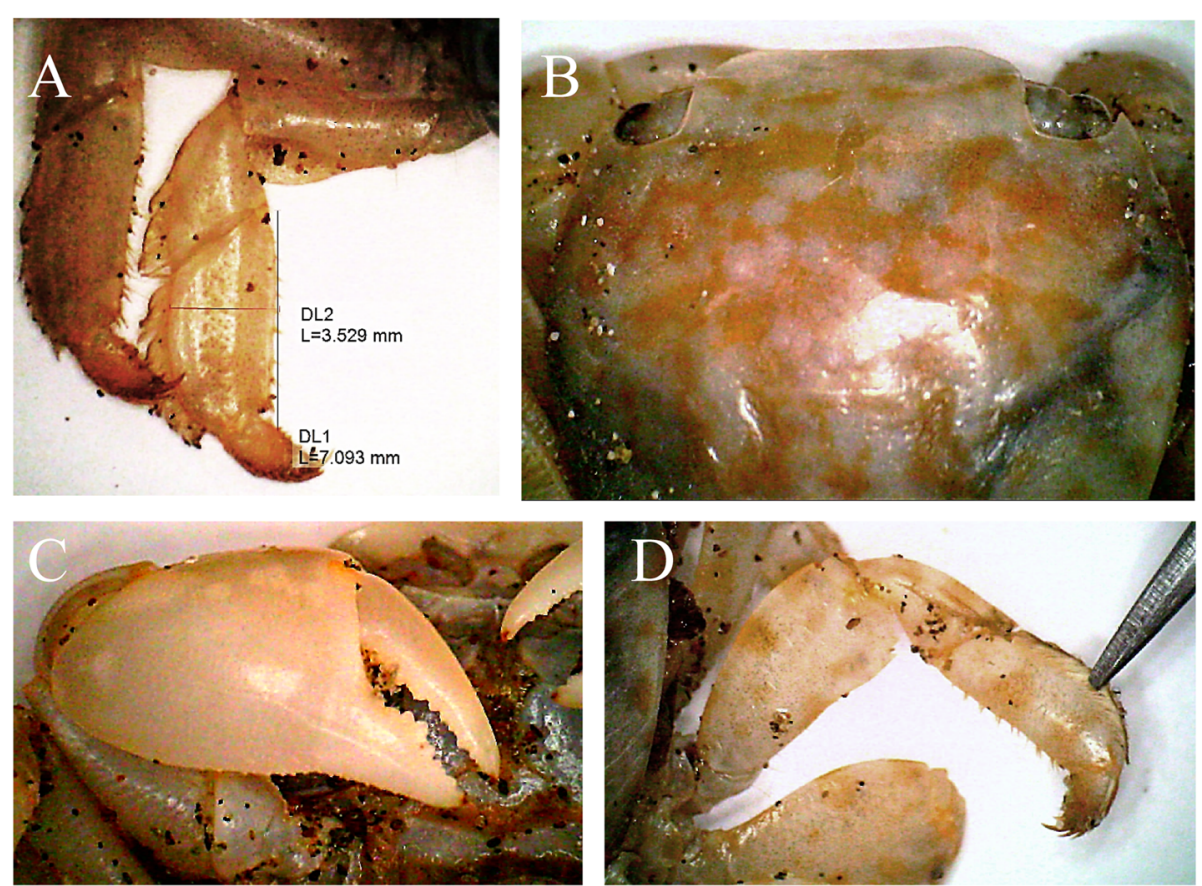

Fig. 3 Female Planes minutus Linnaeus, 1758 collected from the Alqurm Wa Lehhaffaiiah Protected Area on the 11th of January 2018: Propodus of last walking leg [a], carapace laterally convex [b], right female chelipid [c], three distel segments of the second pair of walking legs [d] (Photos: Fadi Yaghmour, 2018) 


\section{Abbreviations}

EPAA: Environment and Protected Areas Authority; P. major: Planes major; P. minutus: Planes minutus; CW: Carapace width; CL: Carapace length;

UAE: United Arab Emirates

\section{Acknowledgements}

The authors express their gratitude for the support of His Highness Sheikh Dr. Sultan bin Mohammed Al Qasimi, Supreme Council Member and Ruler of Sharjah. The authors would also like to acknowledge the support of her Excellency Hana Saif Al Suwaidi, chairperson of Sharjah Environment and Protected Areas Authority, Awatef Al Naqbi, EPAA Khor Fakkan office manager and Dalal AI Yammahi EPAA Kalba office manager.

\section{Authors' contributions}

FY made the initial discovery of the specimen. FY and HN both worked on determining the species ID. All authors have contributed in writing the manuscript and have read and approved the final manuscript.

\section{Funding}

Not applicable.

\section{Availability of data and materials}

Not applicable.

\section{Ethics approval and consent to participate}

In this study all examined specimens were standings collected by authorized staff of the Environment and Protected Areas Authority Scientific Research Department. No ethics approval was required by our internal ethics committee.

\section{Consent for publication}

Not applicable.

\section{Competing interests}

The authors have no competing interests to declare.

\section{Author details}

${ }^{1}$ Hefaiyah Mountain Conservation Centre (Scientific Research Department), Environment and Protected Areas Authority, Sharjah, United Arab Emirates. 2EPAA Kalba Office (Scientific Research Department), Environment and Protected Areas Authority, Kalba, Sharjah, United Arab Emirates.

Received: 6 January 2020 Accepted: 9 July 2020

Published online: 25 July 2020

\section{References}

Al-Ghais S, Cooper R. Brachyura (Grapsidae, Ocypodidae, Portunidae, Xanthidae and Leucosiidae) of Umm Al Quwain mangal, United Arab Emirates. Trop Zool. 1996:9:409-30. https://doi.org/10.1080/03946975.1996.10539320.

Bas CC. First finding of the pelagic crab Planes marinus (Decapoda: Grapsidae) in the southwestern Atlantic. J Crustac Biol. 1999;19(1):72-6.

Branch G, Griffiths C, Branch M. Two oceans. A guide to the marine life of Southern Africa. Cape Town: David Philip; 1994

Carpenter KE. The living marine resources of the eastern Central Atlantic volume 1 introduction, crustaceans, chitons and cephalopods. Rome: Food and Agriculture Organization of The United Nations; 2014

Chace FA. The oceanic crabs of the genera Planes and Pachygrapsus. Proc US Nat Mus. 1951:101:65-103.

Crane J. The Templeton Crocker expedition. III. Brachygnathous crabs from the Gulf of California and the west coast of lower California. Zoologica. 1937; 22(3):47-78.

Davenport J. A cleaning association between the oceanic crab Planes minutus and the loggerhead sea turtle, Caretta caretta. J Mar Biol Assoc UK. 1994;74: 735-7.

Dellinger T, Davenport J, Wirtz P. Comparisons of social structure of Columbus crabs living on loggerhead sea turtles and inanimate flotsam. J Mar Biol Assoc UK. 1997:77:185-94

Frick MG, Williams KL, Bolten AB, Bjorndal KA, Martins $H$. Diet and fecundity of Columbus crabs, Planes minutus, associated with oceanic-stage loggerhead sea turtles, Caretta caretta, and inanimate flotsam. J Crus Biol. 2004;24:350-5.
Frick MG, Williams KL, Pierrard L. Summer time foraging and feeding in loggerhead sea turtles (Caretta caretta) in Georgia. Chelonian Cons Biol. 2001:4:178-81.

Naderloo R. Grapsoid crabs (Decapoda: Brachyura: Thoracotremata) of the Persian Gulf and the Gulf of Oman. Zootaxa. 2011;3048:1-43.

Naderloo R. Atlas of crabs of the Persian Gulf. Cham: Springer; 2017.

Naderloo R, Turkay M. Decapod crustaceans of littoral and shallow sublittoral Iranian coastof the Persian Gulf: faunistics, biodiversity and zoogeography. Zootaxa. 2012;33(74):1-67.

Pfaller JB, Palau AN, Agamboué PD, Barret M, Ciccione S, Cliff G, Formia A, Manfoumbi JC, Marco A, Sounguet GP, Tucker AD. New records of Planes crabs associated with sea turtles in Africa and adjacent waters. Afr J Mar Sci. 2019a;41:331-6. https://doi.org/10.2989/1814232X.2019.1651394.

Pfaller JB, Payton AC, Bjorndal KA, Bolten AB, McDaniel SF. Hitchhiking the high seas: global genomics of rafting crabs. Ecol Evol. 2019b;9(3):957-74

Poppi L, Marchiori E. Standard protocol for post-mortem examination on sea turtles. Network for the Conservation of Cetaceans and Sea Turtles in the Adriatic. 2013.

WoRMS. 2020. Planes minutus (Linnaeus, 1758). Available at http://www. marinespecies.org/aphia.php?p=taxdetails\&id=107462\#notes. Accessed 17 June 2020

\section{Publisher's Note}

Springer Nature remains neutral with regard to jurisdictional claims in published maps and institutional affiliations.
Ready to submit your research? Choose BMC and benefit from:

- fast, convenient online submission

- thorough peer review by experienced researchers in your field

- rapid publication on acceptance

- support for research data, including large and complex data types

- gold Open Access which fosters wider collaboration and increased citations

- maximum visibility for your research: over $100 \mathrm{M}$ website views per year

At BMC, research is always in progress.

Learn more biomedcentral.com/submissions 